Available online at http://www.jfas.info

\title{
INVESTIGATING THE IMPACT OF TOTAL QUALITY MANAGEMENT (TQM) ON INNOVATION IN IRANIAN OIL COMPANIES
}

\author{
M. Sefatian* ${ }^{1}$, H. R. Rezaie Klidbari ${ }^{2}$, A. A. Shojaie ${ }^{3}$ \\ ${ }^{1}$ Masters Student of Business Administration - Change Management, Business Administration \\ Department, School of Humanistic Sciences, Islamic Azad University of Babul, Iran \\ ${ }^{2}$ School of Management and Accounting, Islamic Azad University of Rasht, Iran \\ ${ }^{3}$ School of Humanistic Sciences of Babol BranchIslamic Azad University of Babul, Iran
}

Published online: 15 May 2016

\begin{abstract}
Today, the concept of innovation has captured the attention of many scholars and scientists of different fields, and has gained a paramount importance in modern ever changing organizations for competing with rival's organized management and to survive in the cycle of change. The purpose of the present study is to answer the key question of whether total quality management is able to have any impact on the incremental and radical innovation of Iranian oil companies through cultural changes. This study should be considered as an applicable one in terms of its purpose, a descriptive - correlational one in terms of the method it has followed and a field study in terms of its way of data collection. The sample of the study consisted of 30 Iranian oil Companies, all of which we have thoroughly investigated. The results of the study derived from data analysis done by means of equation modeling method verified all the hypotheses of the study except for hypotheses 2 and 6 . According to our results it is possible to increase the rate of innovation in companies by increasing the level of total quality management.
\end{abstract}

Key Words: Total Quality Management (TQM), cultural changes, incremental and radical innovation, Iranian oil Companies

Author Correspondence, e-mail: mahtab_quen@yahoo.com doi: http://dx.doi.org/10.4314/jfas.v8i3s.267 


\section{INTRODUCTION}

Innovation has been recognized as a necessity for the survival of organizations and as a key concept in the field of marketing and strategic management. Innovations reflect a crucial method based on which organizations respond to market and technology changes. Organizational innovation is defined as: accepting ideas or behaviors in the organization that are novel and unfamiliar. Innovation can be in form of a novel product, a novel service, a novel technology or a novel operational procedure. Innovation plays an important role in the development of companies and in improving their performance. The capacity of innovation is the determiner of optimal performance. Study after study has proved that companies need innovation in order to survive and to gain completive advantages. Companies with high innovation capacities can gain competitive advantages and might optimize their performance through adequate environmental adjustment and developing novel abilities (Taghizadeh Jorshari et al. 2013: 4-5). Companies and organizations aim to develop communication networks in order to improve their capacities for creating and applying innovation (Rehm \& Goel, 2015, p.28). This is due to the curial role of innovation in organizations and companies. Many studies have revealed that innovation can have considerable positive impacts on key variables such as financial or non-financial performance, organizational performance and on gaining competitive advantages (Moon \& Choi , 2014 , P:86). On the other hand, since oil and oil products are considered strategic commodities of Iran, thus investigating the rate of innovation in its oil companies and identifying factors that might influence this key variable is of upmost importance, and might lead to the creation of useful information for improving innovation in such companies.

Several factors might influence innovation and total quality management is one of them. In the present study we have analyzed total quality management in three dimensions of: processes, people and customers (Moreno-Luzon, Gil-Marques, \& Valls-Pasola, 2013). One of the influential experimental studies suggests that process management has a negative effect on radical innovation. The mentioned study had concluded that while implementing $9001-1994$ ISO Standard, increases incremental innovation, it decreases radical innovation at the same time (Benner \& Tushman, 2002).

Cultural values are also among variables that might influence innovation. A series of studies have proved that innovative culture can play a mediating role between total quality management and innovation (Santos-Vijande \& Álvarez-González, 2007). Nevertheless, it is worth 
mentioning that cultural changes are able to influence innovation through changing peoples' views, values and principles that are important to peoples and organizations (Moreno-Luzon, Gil-Marques, \& Valls-Pasola, 2013). In 2011, Luzon and Pasola stated that values and principles have a positive effect on the implementation of total quality management. Creating a cultural change would not be an easy task; this is due to the complexity of cultural values which resists direct manipulation (Luzon \& Pasola, 2011).

With regards to what has been said above, the conceptual model of the study can be viewed in figure1,

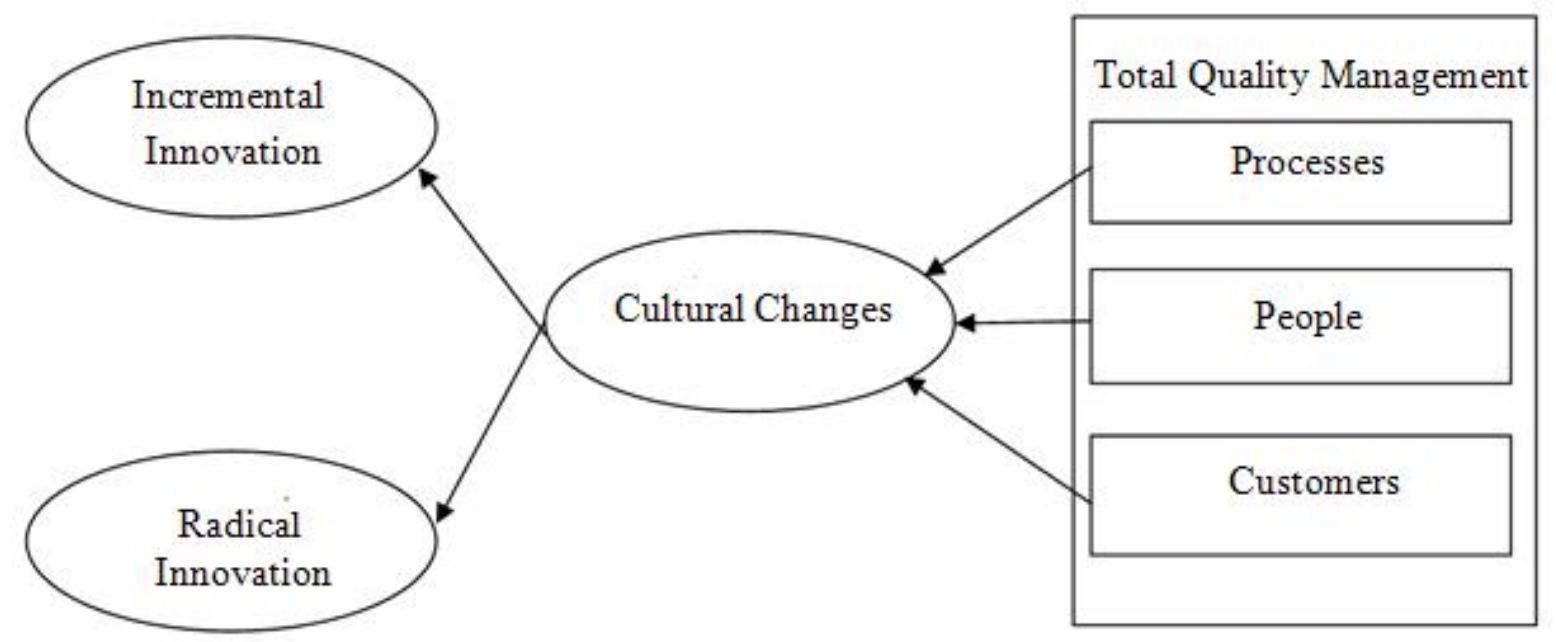

Fig.1. Conceptual Model of the Study (Moreno-Luzon, Gil-Marques, \& Valls-Pasola, 2013)

The chief purposes of the present study are as follows:

- Evaluating the dimensions of total quality management (process, people, customers), cultural changes and incremental and radical innovation in Iranian oil companies

- Evaluating the prevalence of process based total quality management and its impact on innovation in Iranian oil companies

- Evaluating the prevalence of people based total quality management and its impact on innovation in Iranian oil companies

- Evaluating the prevalence of customer based total quality management and its impact on innovation in Iranian oil companies

- Evaluating the mediating role of culture in total quality management and its impact on innovation in Iranian oil companies 
The above purposes will be examined in form of the following hypotheses:

- Hypothesis 1: Considering process based total quality management has an impact on radical innovation in Iranian oil companies

- Hypothesis 2: Considering people based total quality management has an impact on radical innovation in Iranian oil companies

- Hypothesis 3: Considering customer based total quality management has an impact on radical innovation in Iranian oil companies

- Hypothesis 4: Considering process based total quality management has an impact on incremental innovation in Iranian oil companies

- Hypothesis 2: Considering people based total quality management has an impact on incremental innovation in Iranian oil companies

- Hypothesis 1: Considering customer based total quality management has an impact on incremental innovation in Iranian oil companies

\section{Defining the Variables of the Study}

\section{2.1 Total Quality Management}

The word quality has always been businesses' favorite word, and has appeared on the title of many influential studies of marketing and management (Lam, Lee, Ooi, \& Phusavat, 2012, p. 281). Today, quality is defined as one of the most important branches of world competition. The intensifying of world competition and customers' increased demand for improved qualities had led companies and business toward producing high quality products and offering high quality services (Zand-Hessami, Farid, 2013, p:7-8). Total quality management can be defined as the art of controlling all the aspects in order to achieve the best quality, or it can be described as an intelligent, slow and consistent move which would have an empowering effect on achieving the organizations' goals which would consequently satisfy customers' needs, increase efficiency and would add to the capacity to compete in the market (Nouri, 2014, p: 34). Some examples of the objectives of total quality management have been listed as the followings in several sources: (Aghaie, Kolivand, 2014, 46).

- Total customer satisfaction achieved at the lowest cost

- Active participation of all employees in order to eliminate mistakes and avoidance of wastes for creating an improved motivation

- Maintaining current quality and continual improvement 
- Selection and design of adequate technology and processes

- Tangible teaching of quality

- Performance measurement

- Considering the improved point of costs' life cycle

- Increased productivity and added value

- Higher standards

Cullen and Halyngam define total quality management as the process of offering flawless products and services by the organization and maintaining quality in all the aspects of companies' activities. John Pike and Richard Barnes suggest the following definition for total quality management: “ The process of corporate and individual development whose aim is to increase satisfaction level of all the people associated with the organization such as customers, suppliers, stockholders and its employees (Zand-Hesami \& Farid, 2013, : 8).

Abrunhosa views total quality management as a philosophy dedicated to continual refinement and customer satisfaction. Anthony and his colleagues believed that total quality management can increase employees participation, improve relations, increase production, improve quality , reduce wastes, increase customer satisfaction, reduce costs associated with low quality and increase completive advantages (Akbari, Baharestan and Nasr-Isfahani, 2013: 36).

Total quality management (TQM) is a term used for describing a comprehensive approach for quality assurance. In fact, total quality management is a business philosophy which aims to improve products and service quality through active participation of all members of an organization regardless of their level or position (Dubey \& Gunasekaran, 2015, p. 372)

In other words, total quality management is a system which aims to transform firm or organization's culture by presenting novel programs by which continual improvement would be actualized. Therefore, total quality management is the art of managing every aspect of a system in order to achieve the best results (Babatunde \& Low, 2015, p. 15).

\subsection{Culture}

The word "Farhang" which is the Persian synonym for the word culture consists of two parts. The first part "Far" means high, above or forefront and the second part "hang" means intending, pulling and bringing. In the Persian language this word is also equal to the word education. Oxford dictionary also defines culture as: "The arts and other manifestations of human intellectual achievement regarded collectively, or the ideas, customs and social behavior of a 
particular people or society." Amid Persian Dictionary defines culture or Farhang as:"Sciences, literature, knowledge, education and training and scientific and literary achievements of a particular people or society." Moein Persian dictionary also defines culture as: science, knowledge, training, literacy, Intellect and wisdom. Webster defines culture: as a uniform pattern of human knowledge, belief, and behavior depended upon learning capacity and knowledge transfer to the future generations (Mahdavi \& Houshmand 2013, p 109-110).

Schein defines culture: as a pattern of basic shared values and assumptions that the group learned as it solved its problems of external adaptation and internal integration that has worked well enough to be considered valid and, therefore, to be taught to new members as the correct way to perceive, think, and feel in relation to those problems. Schein's definition of culture is a comprehensive one due to its accurate portrayal of basic issues and problems faced by leaders and managers (Marzban \& Ghadami , 2013, p: 29-30).

Culture is a complex concept consisted of different dimensions and elements. Therefore, it has been defined in several ways. Generally , words and phrases such as " the order of meaning", " pattern of meaning" , " order of perceptions" " a form of worldview" , " mental perceptions of reality", " mental order", " shared pattern or standards of perceptions" can be found in most definitions of culture. The above seemingly unrelated words and phrases share a common feature: a series of humans' preserved ideas and beliefs that are pushed by the unconscious (Osareh \& Husaini Bidokht 2014: 93).

\subsection{Innovation}

The English word innovation is defined as the action or process of introducing new ideas, devices or methods. Schumpeter was the first person who viewed innovation as a scientific concept. In fact, Schumpeter wanted to identify the influential factors for economic growth of countries when he accidentally discovered the crucial role of innovation on their growth (Manteghi, Khosrow-Pour and Khani : 2013: 48)

Innovation is the process of collecting any novel and beneficial idea in order to solve problems .Innovation consists of: the formation of an idea and acceptance and implementation of novel ideas in processes, products and services. Since innovation is achieved by implementing new ideas, thus two factors of novelty and beneficiality are an inseparable part of it. Generally, the precondition for novelty is varied since it actualizes a process for innovation in a new invention, a scientific discovery, a method of production or a managerial model. And the beneficiality 
precondition will be achieved by application or commercial success (Karimi, Ahmadi Dastjedri, Rajaie-Pour 2013: 168).

Innovation can be in form of a new idea, a method, a novel and original object or it can only appear novel. Despite the implications of the word "innovation", an innovation does not need to be utterly novel and original; rather it must be ideas, a method or an object which would appear novel in the eyes of its beholders. Therefore, in the process of producing new ideas one should note that appearing novel is more important than the actual novelty. In other words, innovation does not mean that we should throw away anything old and accept everything new, rather it means putting anything that is solid and positive in a dynamic and creative set, regardless of its age (Saied Ardakani et.al, 2013: 137).

Livingstone defines innovation as: the process whereby new ideas are transformed through economic activity, into a sustainable value creating outcome for creative use of information and an efficient human resource management. Chen et al. view innovation as a novel combination of basic factors of production within the production system. The outcome of innovation would be the capacity and ability of the organization in using research and development to create new technologies and novel products in order to satisfy customer. The process of innovation consists of scientific, physical and technical activities all of which play a crucial role in the development of new products. Drucker considered innovation an activity that like all real activities requires the knowledge, attention and effort of all involved in its process, along with their aptitude and talents. He believed that people's common feature is not related to their personalities, rather it is their systematic commitment to innovation (Hadizadeh-Moghaddam, Ghalichli and Moehbbi , 2013: 195).

In his economic theory Schumpeter introduces innovation as "an invention which should lead to at least some amount of market success. "Based on such theory, innovation can be accurately defined as the following equation (Nazari-Zadeh, Mehdinejad Nouri, Hejazi, 2013: 126): Innovation $=$ technological success + market success brought on by innovation Innovation is the creation and acceptance of a novel idea or operational behavior that might lead to operational success. Innovation aims to create value by means of developing ideas that have the potential to be actualized (Noruzy et al., 2013, p. 1076). 
Innovation consists of implementing a novel method in activities, work environment, foreign relations etc that has not been implemented before, and is the outcome of strategic decisions made by managers (Ganter \& Hecker, 2014, p. 1285).

\section{Literature Review}

This section covers some of the studies that have investigated the impact of change management on organizational efficiency. The mentioned studies have been introduced in the following table:

Table 1. Literature Review

\begin{tabular}{|c|c|c|}
\hline Findings & Authors & Column \\
\hline $\begin{array}{c}\text { None of the dimensions of total quality management has a } \\
\text { direct influence on radical innovation, while all of which } \\
\text { positively influence incremental innovation. However, all } \\
\text { the connections can be verified when considering cultural } \\
\text { changes. }\end{array}$ & Luzon et al. 2013 & 1 \\
\hline Total quality management positively influences innovation & $\begin{array}{c}\text { Abrunhosa, A., \& Sa, } \\
\text { (2008) }\end{array}$ & 2 \\
\hline $\begin{array}{l}\text { Total quality management directly, or through } \\
\text { innovativeness influences innovation }\end{array}$ & $\begin{array}{l}\text { Santos et.al } \\
\text { (2007) }\end{array}$ & 3 \\
\hline $\begin{array}{l}\text { Innovativeness as a social value and cultural value can } \\
\text { contribute to the growth and increase in profits of firms } \\
\text { through creating innovation }\end{array}$ & $\begin{array}{l}\text { Cho \& Pucik } \\
\text { (2005) }\end{array}$ & 4 \\
\hline Total quality management impacts innovation & $\begin{array}{l}\text { Prajogo \& Sohal } \\
\qquad(2004)\end{array}$ & 5 \\
\hline $\begin{array}{l}\text { Total quality management optimizes innovative } \\
\text { performances in organizations }\end{array}$ & $\begin{array}{l}\text { Farsijani, Samie' and } \\
\text { Neiestani } \\
\text { (2010) }\end{array}$ & 6 \\
\hline
\end{tabular}

\section{Process of the Study}

The present study was conducted in order to investigate the impact of total quality management on innovation in Iranian oil companies. The hypotheses of this study were formed based on the 
study's theatrical framework and model. Next, we collected our required data by means of using a questionnaire that was collected from the mentioned companies' employees in order to analyze the acquired data and to measure the above mentioned variables. Data analysis was conducted by means of using SPSS2o and visual PLS 1.04 B1 programs.

It is worth mentioning that the questionnaire used in this study had a narrative content and its consistency was verified by the formula of Cronbach's Alpha. In data analysis, the chief distinctions and variables the model were described. Finally, hypothesis evaluation was carried out by means of structural equation modeling method. The present study is an applicable one in terms of its purpose and in terms of its data collection and would be considered as a descriptivecorrelational study due to its investigation and description of the status quo.

The sample of this study consisted of 30 Iranian companies. It is worth mentioning the those companies' field of expertise consisted of : drilling, consulting, Hydrocarbon reservoirs engineering, well services, well exploration, field development and refining companies, whose headquarters were located in Tehran. In this study all 30 companies were investigated and 3-5 filled out questionnaires was collected from each company.

\section{Findings}

1. In regard to the number of employees working in the sample companies, 10 percent of the companies had fewer than 100 employees, $23 / 3$ percent had 100 to 500 employees and 20 percent had up to 500 employees. Also, $46 / 7$ percent of the companies did not disclose the number of their employees. Moreover, 10 percent of the mentioned companies were in business for less than 10 years, $76 / 7$ percent were active for 10 to 50 years and 13/3 percent had a working background of up to 50 years.

The variables of the study can be described as the followings:

- The variable of process had the least amount of: 3/33 and the most amount of: 5. it also had an average of: 4/3167, stranded deviation of: 0/547729 and the variance of 0/3.

- The variable of people had the least amount of: $2 / 6$ and the most amount of: 5. it also had an average of: 4/1533, stranded deviation of: 0/55980 and the variance of 0/313.

- The variable of customers had the least amount of: 1/5 and the most amount of: 5. it also had an average of: 3/8667 stranded deviation of: 0/84009 and the variance of 0/706.

- The variable of radical innovation had the least amount of: 3 and the most amount of: 5 . it also had an average of: 4/1778 stranded deviation of: 0/53055 and the variance of 0/281. 
- The variable of incremental innovation had the least amount of: $2 / 67$ and the most amount of: 5 . it also had an average of: $3 / 3778$ stranded deviation of: $0 / 6879$ and the variance of $0 / 473$.

- The variable of cultural changes had the least amount of: $2 / 83$ and the most amount of: 4/83. It also had an average of: 4/0944 stranded deviation of: 0/55826 and the variance of $0 / 312$.

Also, the normality test on the variables revealed the significance level of the Kolmogorov-Smirnov test for all the variables to be more than $0 / 05$. Therefore, all the variables of the study had a normal distribution. The results of the hypotheses evaluation are listed as follows:

1. The results of the evaluation of the hypothesis regarding the impact of process based total quality management on radical innovation revealed the ratio of t-statistics between two variables to be $4 / 39$. Since the mentioned ratio is higher than $1 / 96$, thus it can be concluded that considering process based total quality management has a positive impact on radical innovation. Also, the ratio of the mentioned impact was determined as $0 / 366$.

2. The results of the evaluation of the hypothesis regarding the impact of people based total quality management on radical innovation revealed the ratio of t-statistics between two variables to be $0 / 041$. Since the mentioned ratio is lower than $1 / 96$, thus this hypothesis cannot be verified. Perhaps this is because, the employees of the sample companies consider paying high-sudden prices for producing a novel product to be illogical and economically wrong.

3. The results of the evaluation of the hypothesis regarding the impact of customer based total quality management on radical innovation revealed the ratio of t-statistics between two variables to be 4/39. Since the mentioned ratio is higher than $1 / 96$, thus it can be concluded that considering customer based total quality management has a positive impact on radical innovation. Also, the ratio of the mentioned impact was determined as $0 / 470$.

4. The results of the evaluation of the hypothesis regarding the impact of process based total quality management on incremental innovation revealed the ratio of t-statistics between two variables to be $3 / 72$. Since the mentioned ratio is higher than $1 / 96$, thus 
it can be concluded that considering process based total quality management has a positive impact on incremental innovation. Also, the ratio of the mentioned impact was determined as $0 / 411$.

5. The results of the evaluation of the hypothesis regarding the impact of people based total quality management on incremental innovation revealed the ratio of t-statistics between two variables to be $2 / 58$. Since the mentioned ratio is higher than $1 / 96$, thus it can be concluded that considering people based total quality management has a positive impact on incremental innovation. Also, the ratio of the mentioned impact was determined as $0 / 18$.

6. The results of the evaluation of the hypothesis regarding the impact of customer based total quality management on incremental innovation revealed the ratio of tstatistics between two variables to be $0 / 723$. Since the mentioned ratio is lower than 1/96, thus this hypothesis cannot be verified. This result might be due to employees' belief, who might think that current customers of targeted markets mostly demand high quality in form of new products, rather than the incremental improvement of the current products.

7. The results of the evaluation of the hypothesis regarding the impact of cultural changes on innovation, considering the study's model the results for when the mediating variable joins the study's model, reveled three items of process, people and customers to be the determiner of $39 / 8$ percent of the variable of cultural changes. Also, all three mentioned items of total quality management had a significant correlation with cultural changes. Cultural changes also have a significant and positive correlation with both items of innovation that is because the t-statistical was above 1/96. Moreover, the result of path analysis for three items of total quality management revealed their impact on incremental innovation and radical innovation to be $0 / 54$ and $0 / 48$ respectively.

It is worth mentioning that the above results are in accordance with all the findings of background studies.

\section{RECOMMENDATIONS}


The following recommendations are presented with regards to the results achieved from summary of study's statistics and from the evaluation of study's hypotheses:

1. Since, the results of statistical analysis for path analysis revealed cultural changes to have the most impact on innovation, thus considering the average ratio of cultural changes question questions, we recommend firms to inform their employees about the importance of creativity and flexibility and to encourage them to shift toward such path, through conducting studies, academic priorities and giving speeches and training,

2. Since, the results of statistical analysis for path analysis revealed process based total quality management to have the most impact on innovation after cultural changes, , thus considering the average ratio of questions, we recommended firms to make better decisions for quality improvement through using more modern processes and information systems, such systems might provide sufficient data for the managers, something that might help them to make better and more accurate decisions. This can be done through academic prioritization that is using the potential of the academic society of the country in order to find problems of the current conditions, and to find novel and applicable solutions.

3. Since, the results of statistical analysis for path analysis revealed customer based total quality management to have the most impact on innovation after cultural changes and process based TQM, thus considering the average ratio of questions, we recommend the designing of a system that would collect customer and consumers' feedbacks through a web based system in order to study and implement them. Then, using the same website, the public should be informed of the implemented changes that have taken place due to their feedbacks.

4. Finally, we recommend paying more attention to subjects such as service and product quality in writing of the organization's general policies and strategies. We also recommend the active participation of all employees in such activities in order for them to gain a compressive knowledge of the firm's polices and strategies.

\section{Limitations of The study}

1. Since most Iranian oil companies are geographically scattered, the required data of the present study was collected from the representatives of those companies gathered at an exhibition. 
2. In the present study, the level of study's variables was measured between all companies, all together.

\section{Future Research Suggestions}

1. We suggest the data collection of future researches and studies to be through physical show up at sample companies for the distribution of the questionnaire $s$ between their middle and high rank employees.

2. We suggest a comparative method for the future researches and studies, so that the sample companies could be compared with each other.

\section{SOURCES AND REFERENCES}

1. Aghaie, A, Kolivand , H, 2014, “Investigating the Impact of Total Quality Management on the Performance of Vice Chancellor Office of Amad and the Naja Support Center" Seasonal Scientific Journal of Amad Thought, (49) 13, 39-58

2. Akbari , P, Baharestan , A, Nasre_Isfahani , A, 2013, “Analyzing the Mediating Influence of Organizational Learning in the Relationship between Total Quality Management and Innovative Performance : a Case Study on Iran Darou Company", Journal of Industrial Management, (23) 8, 35-46

3. Taghizade Jorshari, M, Ziadid, A, Ta'khireh M, Inrahimnejad, M, 2013, “ The Influence of Market Based Policies on Novel Services: The Role of Service Innovation : a Case Study on Insurance Firms of Gilan Province" , The second national conference of Innovative Management, Gorgan, Hakim Jorjani Private High Education Institute

4. Zand Hessami, H, Farid, S, 2013, “ Investigating the Influence of Different Dimensions of Total Quality Management on Mass Custom Production" , Journal of Development and Change Management , (13) 5, 17-17

5. Saieda Ardakani, S, Konjkav-Monfared, A, Hakkaki, S,M, Rezaie Dowlat Abadi, H, 2013, “ Identifying the Influential Factors on Developing Individual Innovation" Journal of Technological Development Management, (2), 135-155

6. Osareh , A, Husaini-Bidokht M, 2014, “ Investigating the Impact of Extending Higher Education Institutes in Relation to Culture and Cultural Bombardment" Journal of Iranian Social Development, (2) 6, 100-191 
7. Farsijani, Hassan, Neistani , V, Abulfazl Sami'ie, 2010, "Investigating the Role of Uniformity between Total Quality Management and Technology Management in Quality and Innovation Performances : a Case Study on Firms of Markazi Province " Journal of Information Technology Management, (4) 2, 117-136

8. Ghadami, M, Marzban, A , 2013, “The Relationship between Culture and Organizational Structure Complexities: a Case Study on Iranian National Television" Journal of Cultural Management, (19) 7, 25-40

9. Karimi , F, Ahmadi Dastjerdi, S, Rajaie Pour , S, 2013, "The Structural Model of the Relationship between Social Capital and the Capacity of Organizational Learning and Employees Innovation" Journal of Productive Management, (27) 7, 165-182

10. Manteghi , M, Khosrowpour, H, Khani, M, 2013, “Prioritizing the Influential Factors on Innovation " The institute of Commercial Studies and Researches, Journal of Industrial Management, (23) 8, 47-61

11. Mahdavi , Gh, Hooshmand , A, 2013, “Investigating the Impact of Ethical Culture of the Organization on the Behavior of Accountants", Journal of Accounting Science, (51) 13, 107 126

12. NazariZadeh , F, Mehdinejaz Nouri, M, Hejazi, S, 2013, “Investigating the Influence of Individual Factors on the Success of Innovation in Iranian Defense Industry" Journal of Management Improvement, 123-128

13. Nouri , GH, 2014, “ Total Quality Management (TQM)”, Journal of Transportation and Development, (82), 33-38

14. Hadizadeh Moghaddam, A, Ghalichli, B, Mohebbi, P, 2013, “Investigating the Relationship between Sharing Science and Innovation in Financial Service Institutions: Iranian Bank of Refah Kargaran", Journal of Iranian Management Studies" (1) 17, 187-207

15. Abrunhosa, A., \& Sa, P. M. E. (2008). «Are TQM principles supporting innovation in the Portuguese footwear industry? Technovation”, 28(4), 208-221.

16. Babatunde, Y., \& Low, S. P. (2015). Review of Literature on TQM and National Culture Cross-Cultural Management and Quality Performance (pp. 11-29): Springer.

17. Benner, Mary J, \& Tushman, Michael. (2002). "Process management and technological innovation: A longitudinal study of the photography and paint industries”. Administrative Science Quarterly, 47(4), 676-707. 
18. Cho, H. J., \& Pucik, V. (2005). "Relationship between innovativeness, quality, growth, profitability, and market value". Strategic management journal, 26(6), 555-575.

19. Dubey, R., \& Gunasekaran, A. (2015). "Exploring soft TQM dimensions and their impact on firm performance: some exploratory empirical results." International Journal of Production Research, 53(2), 371-382.

20. Ganter, A., \& Hecker, A. (2014). "Configurational paths to organizational innovation: qualitative comparative analyses of antecedents and contingencies." Journal of business research, 67(6), 1285-1292. doi: 10.1016/j.jbusres.2013.03.004

21. Lam, S.-Y., Lee, V.-H., Ooi, K.-B., \& Phusavat, K. (2012). «A structural equation model of TQM, market orientation and service quality: Evidence from a developing nation" Managing Service Quality: An International Journal, 22(3), 281-309.

22. Luzon, Maria D Moreno, \& Pasola, Jaume Valls. (2011).” Ambidexterity and total quality management: towards a research agenda. Management Decision," 49(6), 927-947

23. Moon, H. K., \& Choi, B. K. (2014). "How an organization's ethical climate contributes to customer satisfaction and financial performance: Perceived organizational innovation perspective." European Journal of Innovation Management, 17(1), 85-106. doi: 10.1108/ejim-03-2013-0020

24. Moreno-Luzon, M. D., Gil-Marques, M., \& Valls-Pasola, J. (2013). «TQM, innovation and the role of cultural change". Industrial Management \& Data Systems, 113(8), 1149-1168.

25. Rehm, S.-V., \& Goel, L. (2015). "The emergence of boundary clusters in interorganizational innovation." Information and Organization, 25(1), 27-51. doi: 10.1016/j.infoandorg.2014.12.001

26. Santos-Vijande, M. L., \& Álvarez-González, L. I. (2007). «Innovativeness and organizational innovation in total quality oriented firms: The moderating role of market turbulence." Technovation, 27(9), 514-532.

27. Prajogo, D. I., \& Sohal, A. S. (2004). "The multidimensionality of TQM practices in determining quality and innovation performance - an empirical examination" Technovation, 24(6), 443-453.

28. Noruzy, A., Dalfard, V. M., Azhdari, B., Nazari-Shirkouhi, S., \& Rezazadeh, A. (2013). "Relations between transformational leadership, organizational learning, knowledge management, organizational innovation, and organizational performance: an empirical 
investigation of manufacturing firms" The International Journal of Advanced Manufacturing Technology, 64(5-8), 1073-1085.

How to cite this article:

Sefatian M, Rezaie Klidbari HR, Shojaie AA. Investigating the impact of total quality management (tqm) on innovation in iranian oil companies. J. Fundam. Appl. Sci., 2016, $8(3 S)$, 869-884. 